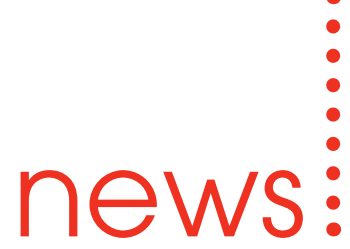

\section{Luton gets go-ahead}

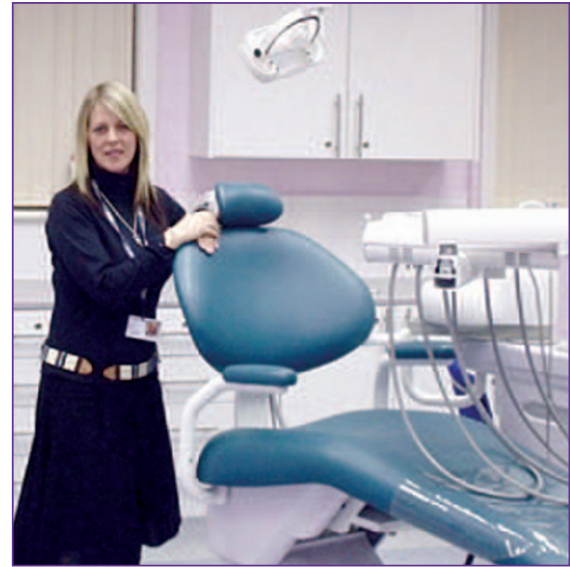

Angie McBain at Barnfield College's new dental unit

Barnfield College Luton is launching a foundation degree in dental nursing and a new dental nurse cadet programme. The goahead is subject to university validation and accreditation by the General Dental Council (GDC). Angie McBain, the lead tutor and President-elect of the British Association of Dental Nurses said, 'The part-time foundation degree, over two calendar years, is being taught at Barnfield with the degree awarded by the University of Bedfordshire. It will allow dental nurses to become more involved with patient care - undertaking x-rays, oral health, education and smoking prevention. The two-year cadet course will include a GCSE in physiology and health, an AS level in biology and a foundation certificate for oral health promotion. On successful completion of the cadet programme, students will be qualified dental nurses eligible for registration with the GDC.'

Ms McBain added that the foundation degree would further develop the skills of qualified dental nurses and provide a possible career pathway to other areas of dentistry and health care.

Both courses start in September with the initial intakes expected to be between 12-15 students. Much of the training will be undertaken at the college's brand-new dental unit which features a fitted surgery. Apart from Barnfield's team of dental nurse tutors, outside experts will be brought in for part of the courses.

\section{New dental school appointment}

Dr Jonathan Bennett has been appointed by the Peninsula Dental School as Senior Lecturer in Dental Education. A graduate of the Universities of London and Oxford in Dentistry, Science and Education, Jon Bennett has contributed extensively to both undergraduate and graduate dental courses in the UK and overseas.

$\mathrm{He}$ has a special interest in teaching applied basic science in dentistry supported by extensive experience of biomedical research and clinical work in the fields of Oral Surgery, Oral Medicine and Oral Pathology.

The Peninsula Dental School is a new initiative designed to take a fresh approach to the teaching and development of prospective dentists and to ensure its graduates are best prepared to rise to the oral health challenges of the future.

The School will welcome its first cohort of students in September 2007 to the Bachelor of Dental Surgery (BDS) degree course.

\title{
Oral health prevention in nurseries
}

Children in nurseries around Scotland had something to smile about recently as the second of two major Scottish Oral Health Demonstration programmes was launched near Dunfermline, Fife by the Deputy Health Minister for Health and Community Care, Scotland, Lewis Macdonald.

The programme will deliver a targeted oral health prevention programme in nurseries and primary schools, initially focusing on the twice yearly application of fluoride varnish by specially trained clinical dental teams.

Supported by a fleet of vehicles, the teams will comprise dental hygienists and dental nurses, and a new programme to train dental nurses to apply fluoride varnish is under development. Both Childsmile programmes will also introduce the role of dental health support worker. The Childsmile programmes have been funded through Scotland's Dental Action Plan with Childsmile (East) involving six NHS Board areas.

For more details see www.child-smile.org.

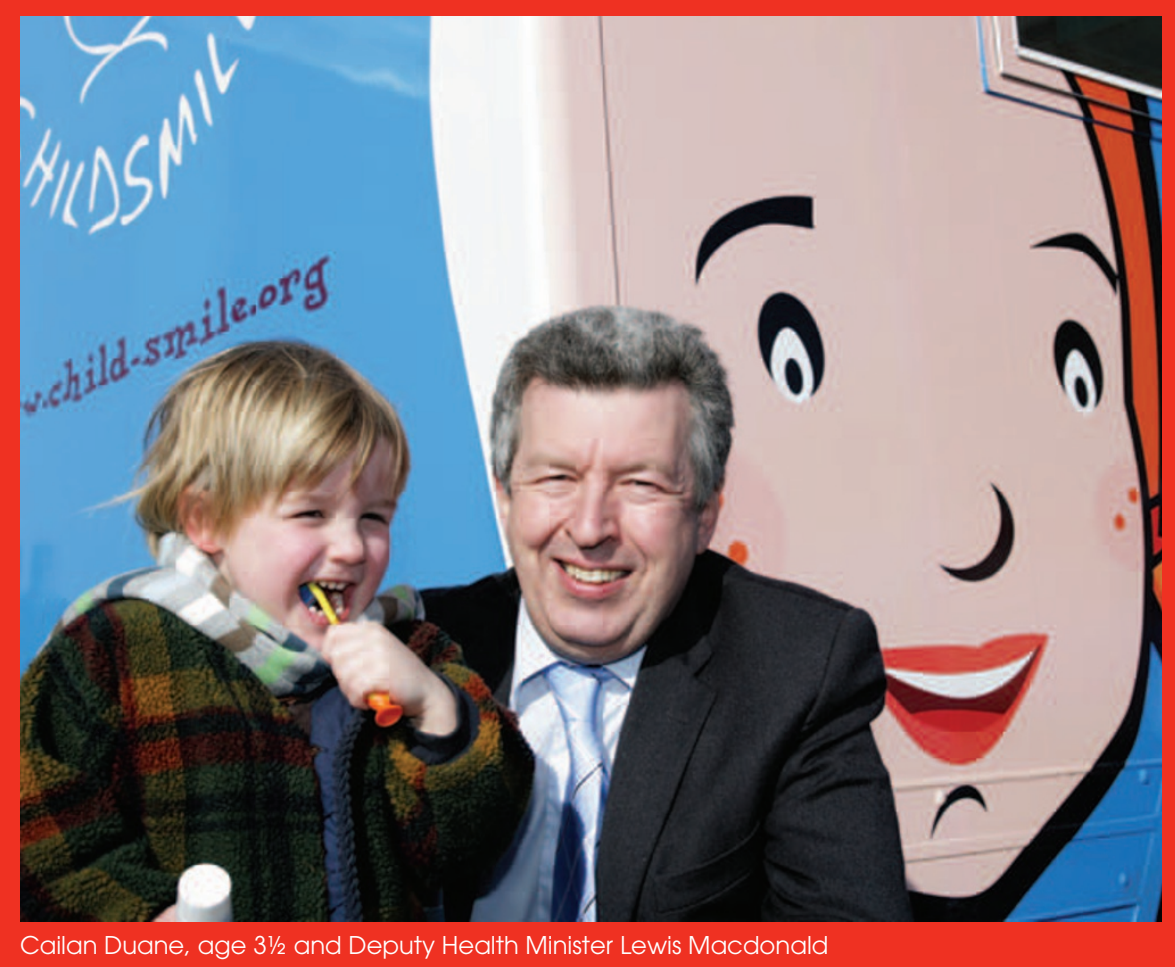

